\title{
Smoking Cessation in Pregnancy: A Review of Postpartum Relapse Prevention Strategies
}

\author{
Wei Li Fang, PhD, Adam O. Goldstein, MD, Anne Y. Butzen, S. Allison Hartsock, \\ Katherine E. Hartmann, MD, PhD, Margaret Helton, MD, and Jacob A. Lohr, MD
}

Objective: Review and examine existing research, current strategies, and directions for future research on smoking cessation relapse and relapse prevention in pregnancy and postpartum.

Methods: A MEDLINE/PubMed search in 2002 and 2003 for articles containing the key words "smoking," "pregnancy," "cessation," and "cessation relapse prevention" and references of retrieved papers yielded a review of more than 500 articles. Only 14 of these addressed program-based strategies to increase cessation among pregnant women through relapse prevention programs.

Conclusion: Although there is much information on the rationale and strategies for smoking cessation for pregnant women, fewer studies exist on how to prevent relapse. Maintaining and accelerating progress in cessation during pregnancy and postpartum requires more research that focuses on relapse prevention and cessation. Programs should incorporate stresses particular to postpartum women, should be part of routine health care, and should involve the woman's social support network, including her partner, to maximize effectiveness. (J Am Board Fam Pract 2004;17:264 -75.)

Throughout the past decade, tobacco use has remained the single most important modifiable cause of poor pregnancy outcome in the United States. Smoking accounts for $20 \%$ of deliveries of infants with low birth weights, $8 \%$ of preterm births, and $5 \%$ of all perinatal deaths. Smoking during pregnancy and in postpartum contributes to sudden infant death syndrome and changes in brain and nervous system development. The direct medical costs of a complicated birth for a smoker are $66 \%$ higher than for nonsmokers. ${ }^{1}$

Relapse rates range from $70 \%$ to $85 \%$ among women who smoke but quit at some time during their pregnancy. A recent 10-year study (1987 to 1996) of 8808 pregnant women and 178,499 nonpregnant women of childbearing age indicated that the prevalence of current smoking has decreased significantly among both pregnant $(16.3 \%$ to

Submitted, revised, 13 November 2003.

From the Governor's Institute on Alcohol and Substance Abuse, Research Triangle Park, North Carolina (WLF, SAH, JAL), University of North Carolina School of Medicine, Chapel Hill (WLF, KEH, JAL), and University of North Carolina Department of Family Medicine, Chapel Hill (AOG, AYB, MH). Address correspondence to Wei Li Fang, PhD, Governor's Institute on Alcohol and Substance Abuse, Inc., PO Box 13374, Park Office Suite 200, Research Triangle Park, NC 27709-3374 (E-mail: wlfang@ mindspring.com).
$11.8 \%)$ and nonpregnant women $(26.7 \%$ to $23.6 \%)^{2}$ This drop in smoking over time among pregnant women was primarily caused by the overall decline in smoking initiation rates among women of childbearing age, not by an increased rate of smoking cessation related to pregnancy.

Although one fifth of pregnant smokers spontaneously quit by the time of their first antenatal visit, ${ }^{3}$ and pregnant women are half as likely as nonpregnant women to be smokers, ${ }^{2}$ an estimated $20.4 \%$ of women smokers continue smoking throughout their pregnancies. ${ }^{4}$ For women who do quit during pregnancy and who received a planned intervention, between $6.2 \%$ and $37.2 \%$ remained smoke-free. The range of relapse rates is broad because of the varying success of the cessation intervention strategy. Between $29 \%$ and $85 \%$ of women who get a planned intervention relapse after delivery. ${ }^{5-16}$

Although there is much information on why and how pregnant women should quit, fewer data exist on how to prevent relapse. This article is a literature review on relapse and relapse prevention in pregnancy; we looked at existing research, current strategies, and directions for future research.

\section{Methods}

A MEDLINE/PubMed search was performed in 2002 and 2003 for articles containing the key words 


\begin{tabular}{|c|c|}
\hline Factors Influencing Pregnant Women to Quit & Factors That Trigger Postpartum Women to Smoke Again \\
\hline \multicolumn{2}{|l|}{ Pregnancy Related } \\
\hline Planned pregnancy & Entering postpartum \\
\hline Morning sickness & Stress of caring for a newborn \\
\hline Becoming visibly pregnant & Weaning from breast-feeding \\
\hline \multicolumn{2}{|l|}{ Decision to breast-feed } \\
\hline \multicolumn{2}{|l|}{ Social Reasons } \\
\hline Social pressures & Partners who smoke \\
\hline Guilt & Social pressures \\
\hline \multirow[t]{2}{*}{ Social support } & $\begin{array}{l}\text { Familiar cues such as drinking alcohol or coffee/tea, after meals, } \\
\text { on the phone, in the car, etc. }\end{array}$ \\
\hline & Exposure to high-risk situations \\
\hline \multicolumn{2}{|l|}{ General Health of Self and Others } \\
\hline Baby's health & Need time for self \\
\hline Children with asthma or other respiratory problems & Under pressure from children \\
\hline \multirow[t]{3}{*}{ Personal health reasons } & Trying to relax \\
\hline & Feeling sad and irritable \\
\hline & Weight gain \\
\hline \multicolumn{2}{|l|}{ Clinical Interventions } \\
\hline \multicolumn{2}{|l|}{ Participation in a cessation program } \\
\hline Advice from a physician or other health care provider & \\
\hline
\end{tabular}

"smoking," "pregnancy," "cessation," and "cessation relapse prevention." As of October 28, 2003, MEDLINE/PubMed indexed 4132 biomedical and life sciences journals. This search yielded a review of more than 500 articles. In addition, references of retrieved articles were reviewed to identify additional sources. All relevant articles were reviewed, with a closer examination of postpartum smoking cessation and relapse. To be included in this review, articles had to address pre- or postnatal relapse prevention or treatment. Articles were also included if they allowed comparisons of women who relapsed versus those who remained smoke free. Of the 146 articles that contained references to postpartum relapse, only 14 specifically described strategies to increase cessation among pregnant women through relapse prevention programs ( 2 of these 14 articles discussed the same program). Four of the investigators systematically reviewed and analyzed these articles.

\section{Results}

\section{Profiles of Women Who Smoke and Are Pregnant}

Researchers have reported that specific events, factors, or decisions precipitate a pregnant woman's resolution to quit (Table 1). Important factors include planned pregnancy, ${ }^{17}$ morning sickness, ${ }^{2,18}$ becoming visibly pregnant, ${ }^{2}$ decision to breastfeed, ${ }^{2,19}$ personal health reasons, ${ }^{2,3,18}$ baby's health, ${ }^{2,3,18}$ children with asthma or other respiratory problems, ${ }^{17}$ social pressures, ${ }^{2}$ guilt, ${ }^{2}$ advice from a physician or other health care provider, ${ }^{14}$ participation in a cessation program,,${ }^{9,10,14,15}$ and a good opportunity to quit. ${ }^{18}$

According to DiClemente et $\mathrm{al}^{20}{ }^{20}$ pregnant women and their smoking status can be categorized into 3 types: those who quit because they are trying to get pregnant (pregnancy quitters), women who quit immediately after learning they are pregnant (spontaneous quitters), and women who smoke throughout pregnancy (pregnant smokers). Little is known about pregnancy quitters; they are generally labeled as nonsmokers because they quit before their first prenatal assessment, and they are not offered cessation counseling or support. In theory, pregnancy quitters might be more conscientious of their own health and their baby's health than spontaneous quitters and pregnant smokers and might be dedicated to remaining smoke-free not only for pregnancy but also for life. DiClemente et $\mathrm{al}^{20}$ found that these women typically sustain cessation throughout the prenatal and postpartum period and that cessation rates on follow-up are dependent on their addiction (measured by number of ciga- 


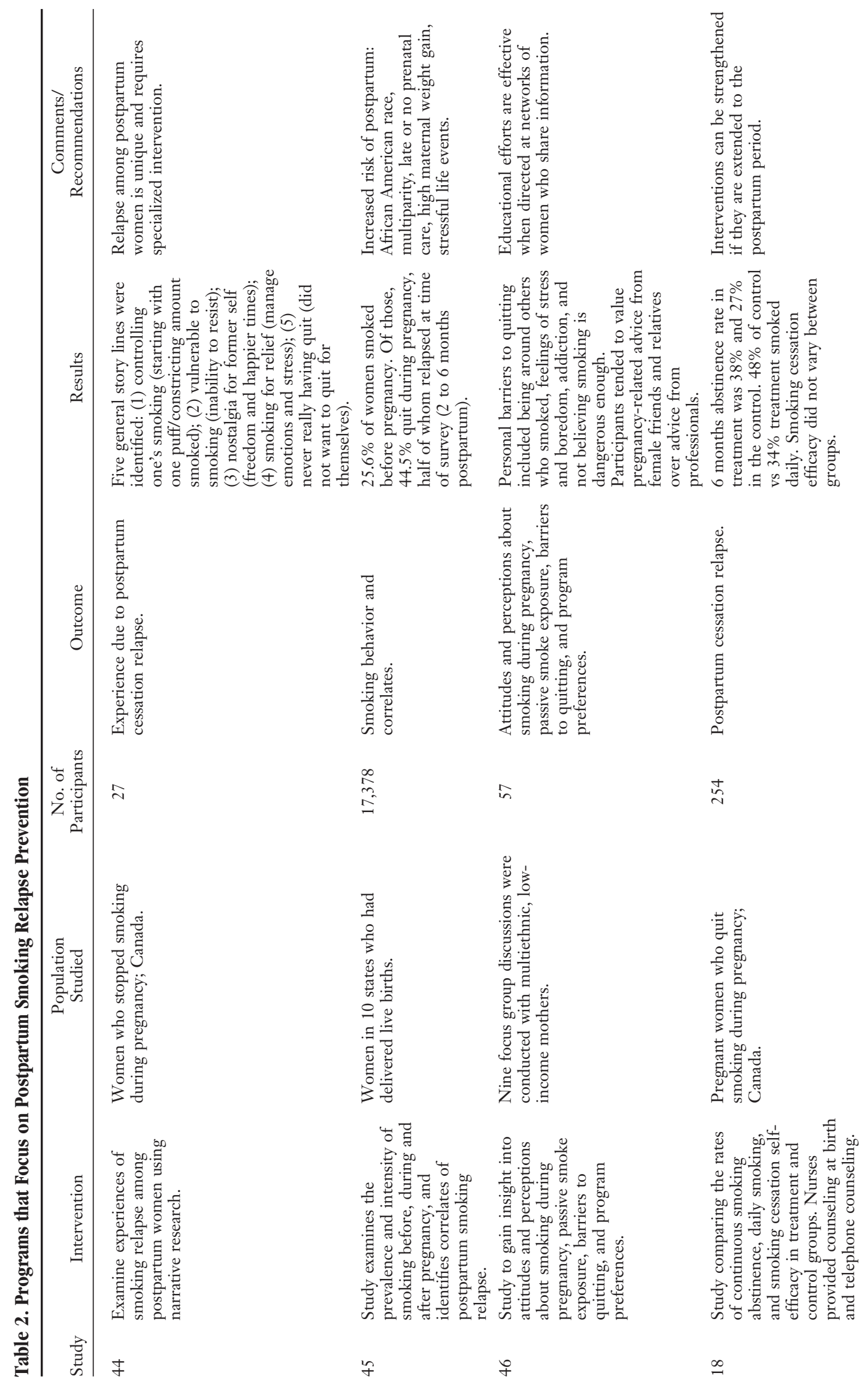




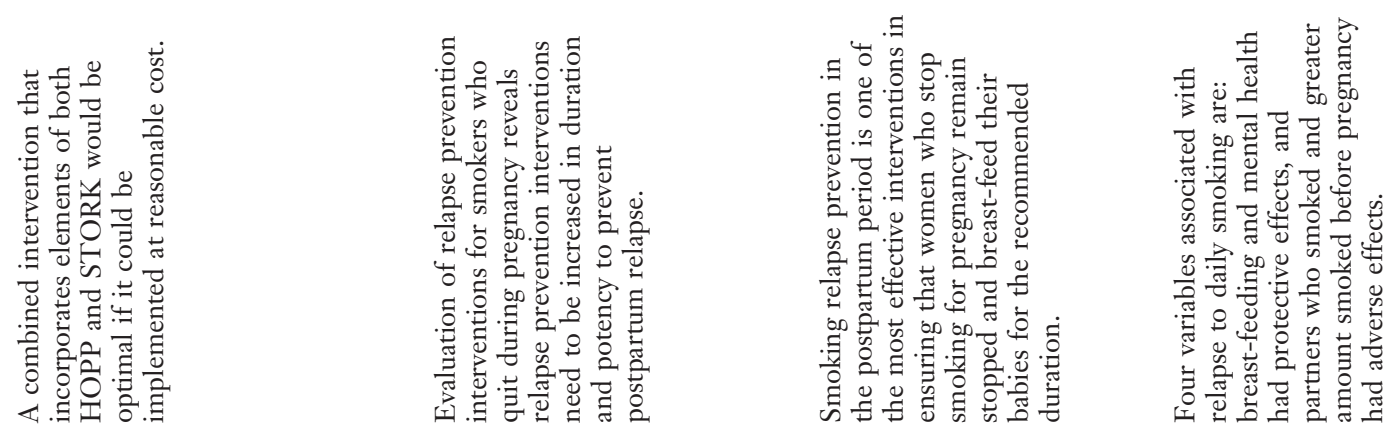

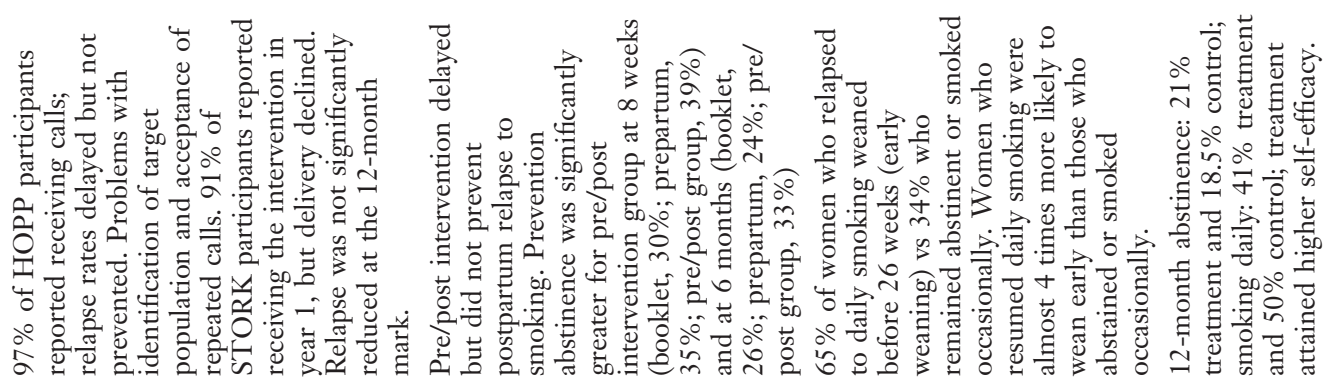
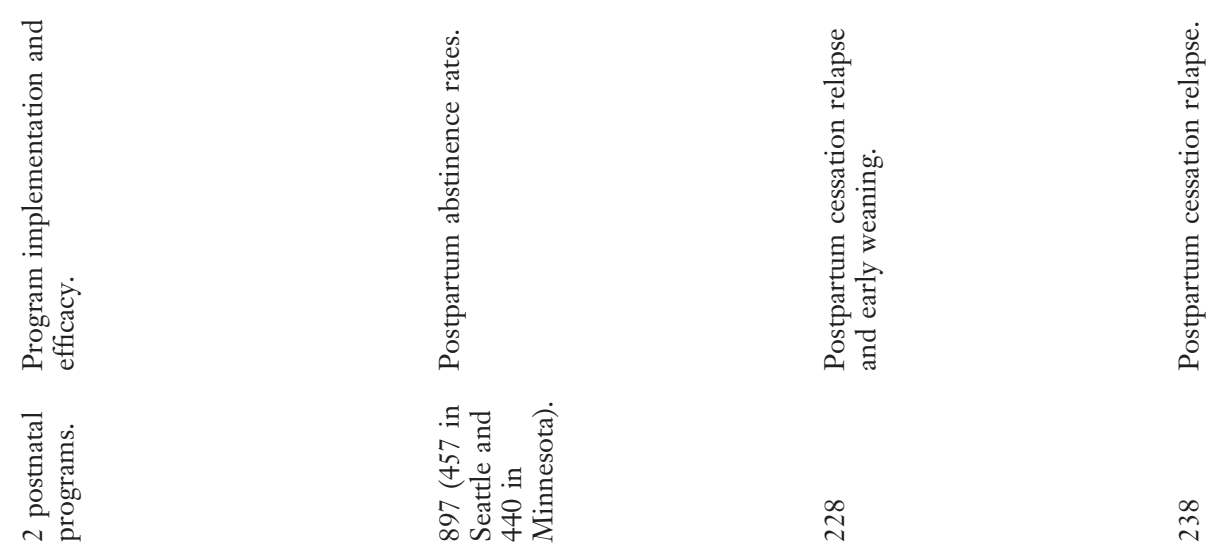

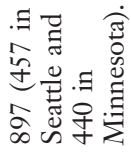

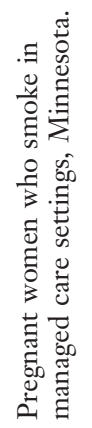

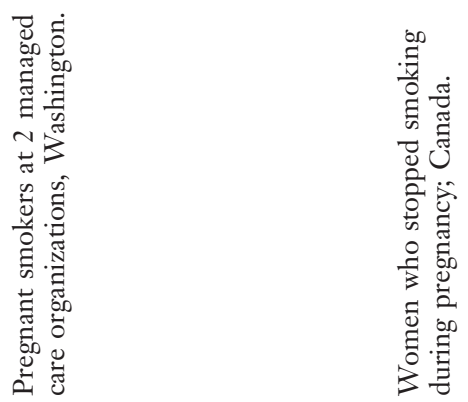

$\stackrel{\infty}{\text { สิ }}$

$\stackrel{\infty}{\sim}$
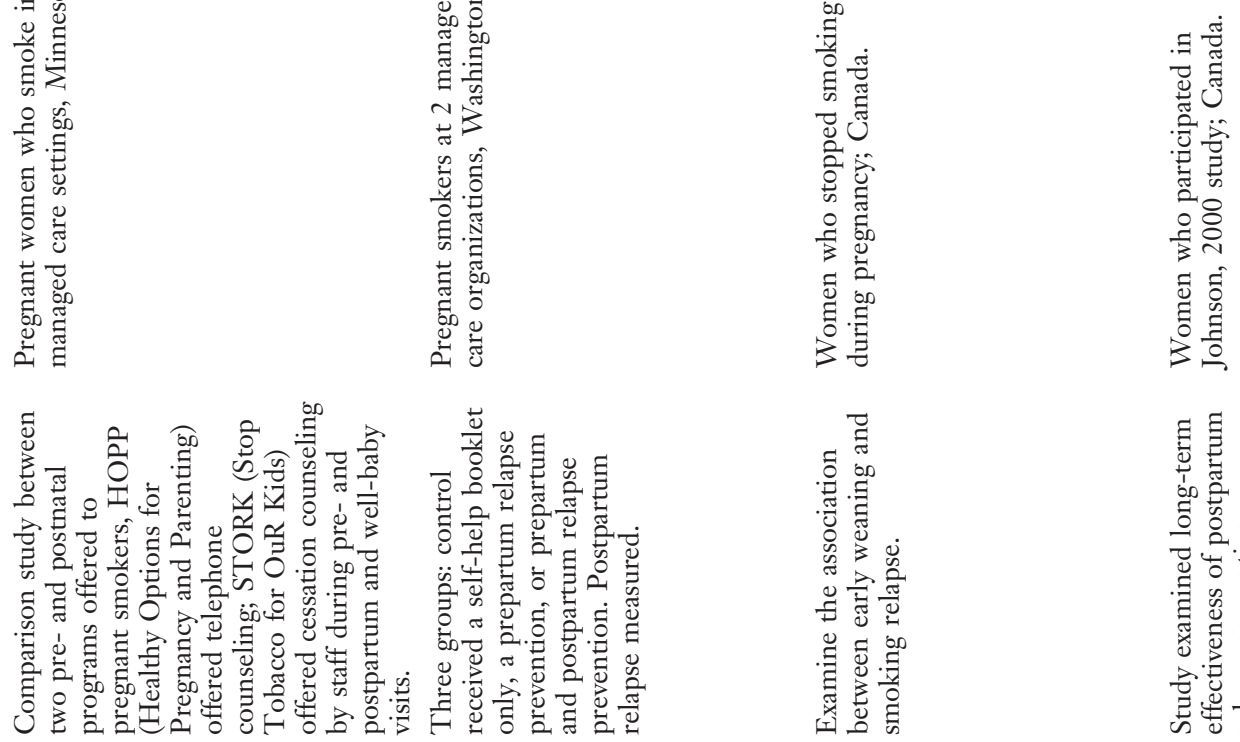

$$
\text { f }
$$$$
=
$$

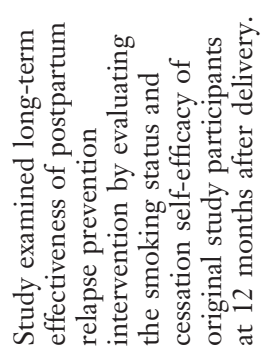

in 


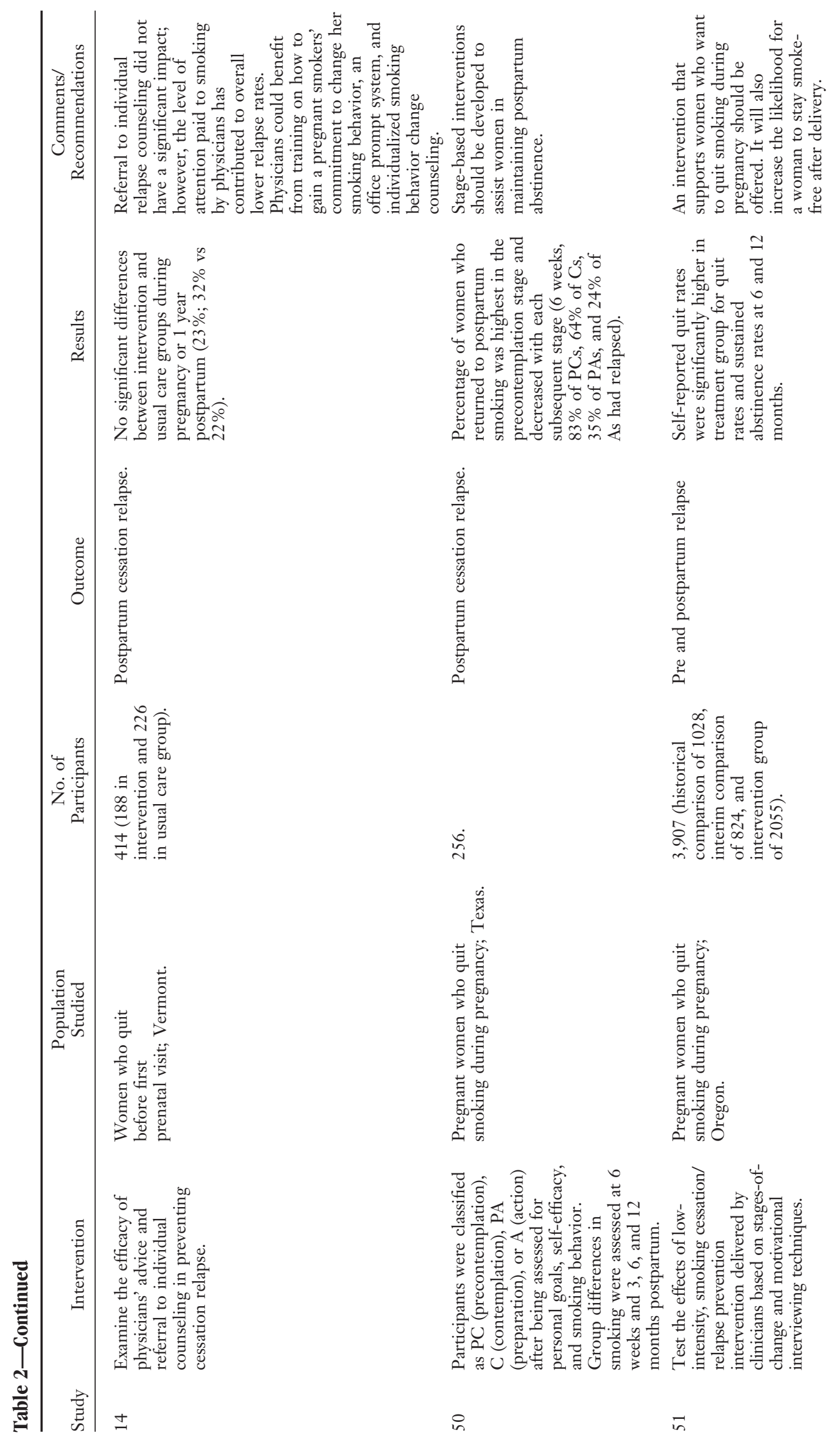




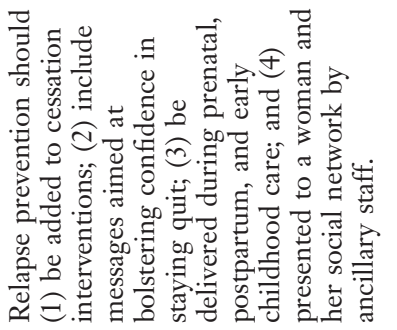

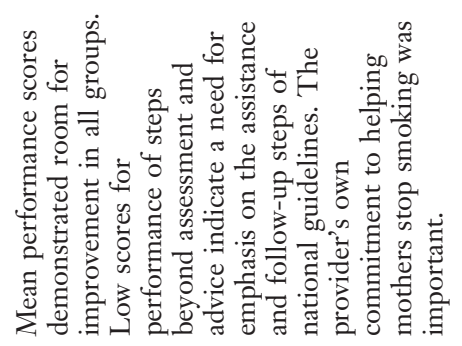

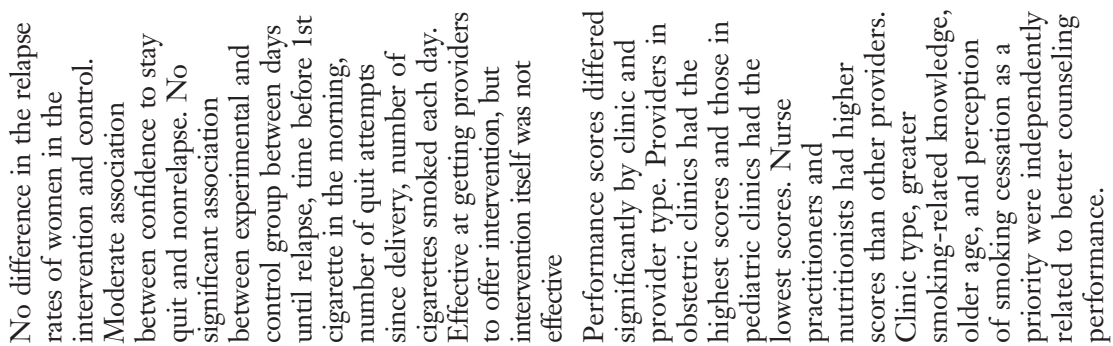

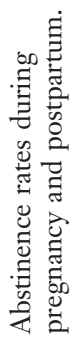

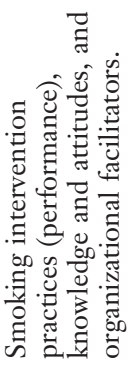

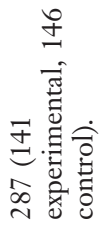

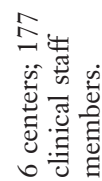

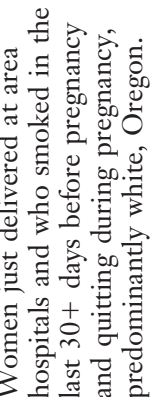

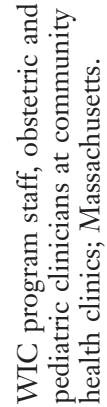

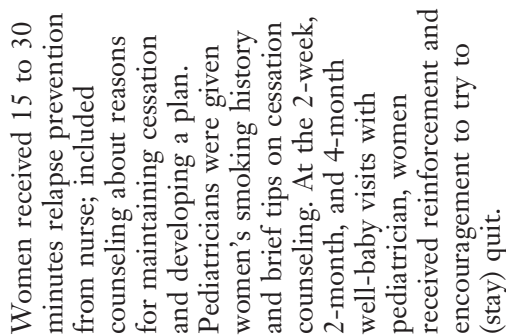

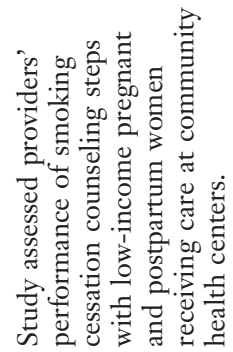

in

in

음. 
rettes smoked per day, length of time between waking and smoking the first cigarette, etc) and motivation to quit.

Spontaneous quitters generally have high cessation rates throughout the pregnancy ( $80 \%$ to $85 \%)$. Panjari et $\mathrm{al}^{3}$ found that spontaneous quitters are different from other smokers in a range of demographic variables (ie, race, educational level, income, and employment status), their contented addiction, and beliefs about the risks. However, more than $70 \%$ of spontaneous quitters will relapse within 6 months after delivery. High relapse rates occur, in part, because the motivation to quit is fueled by a desire to protect an unborn baby. Many women might not appreciate or be aware of the adverse health effects on children of exposure to environmental tobacco smoke. ${ }^{5,21}$ Preparing women to move from an awareness of smoking on the developing baby to an effect on themselves is fundamental in maintaining cessation. ${ }^{20,21}$

Pregnant smokers are more likely to come from the subgroup of women with lower socioeconomic status. ${ }^{20}$ These women tend to have more psychological and emotional problems, less support and financial resources, more family problems, and less residential security. ${ }^{20,22-30}$ Low-income pregnant women report

“... more stressful events, more perceived stress, more negative appraisal from family, less social support of all types, lower scores on mental health measures, and more addiction to cigarettes. These conditions lower motivation to stop smoking and also self-confidence in an ability to stop." 31

\section{Profiles of Women Who Relapse Postpartum}

Those who relapse postpartum tend to be young women who were heavy smokers before pregnancy and women who quit smoking late during pregnancy (in the third trimester). ${ }^{5}$ Successful quitters tend to be light to moderate smokers, ${ }^{5,6}$ white, married, young, and educated. ${ }^{32,33}$ When Edwards and Sims-Jones ${ }^{34}$ interviewed 22 women who smoked before pregnancy and had relapsed postpartum, 3 themes emerged: pregnancy as a context for stopping smoking, specific events and stressors that precipitated a return to smoking, and social influences on smoking behavior. For those who relapsed, relationship troubles, medical problems, and other stressful events triggered a return to smoking. Other contributors included returning to a nonpregnant state, social pressures, and high-risk situations. Hospitalization after delivery prolonged the smoke-free state, and this period might be a time to reinforce maintenance. Others have found that women with partners who smoke find it more difficult to quit and not relapse (Table 1). 9,19,35,36

Some research shows that advantages for smoking cessation focus on the baby whereas disadvantages for stopping are related to the mother. ${ }^{34}$ The specific events, factors, or decisions that precipitate a woman's resolution to quit are not necessarily the same as those that trigger a woman to smoke again.

\section{Interventions that Maintain Smoking Cessation during Pregnancy}

Most research on smoking cessation and pregnancy has attempted to maintain cessation during pregnancy (Table 2). Programs that support women during this time protect the health of the unborn baby as well as the pregnant mother. Several programs keep high-risk women from smoking during pregnancy but do not track whether the women remain smoke-free after the baby is born. ${ }^{32,37,38}$ Although factors that cause women to return to smoking after pregnancy are not identical to those causing women to return to smoking while pregnant, it is useful to look at studies of programs that encourage women to quit smoking while pregnant.

Ershoff and his colleagues ${ }^{25}$ outlined 3 possible strategies for maintaining prenatal cessation among women who quit during pregnancy: targeting, triage, and tailoring. Targeting would maximize considerable resources in helping women with low intentions of quitting by simultaneously addressing attitudinal, addiction-related, and environmental barriers. Triage would recognize that health care providers have a finite amount of time and resources to invest in helping pregnant women stop smoking, and a better strategy is to devote more resources to those pregnant smokers with the motivation to quit. Tailoring would recognize the barriers to quitting faced by pregnant smokers with low quitting intentions, acknowledge that the goal of quitting smoking during pregnancy might be unrealistic, and help those women with a harmreduction approach. ${ }^{25}$ Harm reduction counsels women to cut down on the number of cigarettes smoked in lieu of complete cessation. This might indeed be a useful strategy when combined with 
counseling about other healthy lifestyles (eg, healthy eating, daily exercise). ${ }^{20}$ The smoking status of their partner, close friends, and family affect all women who smoke and are pregnant. ${ }^{20,22,28,39,40}$

A promising strategy for assisting low-income women is to use stages of change and decisional balance constructs. Bane and her colleagues ${ }^{21}$ studied participants who completed the general 8-item decisional balance measure ( 4 pros and 4 cons) plus 8 additional pregnancy-related items (4 pros and 4 cons) to determine this underlying structure of pregnancy-tailored decisional balance measure. The pros addressed the perceived benefits of smoking, such as relaxation and pleasure, whereas the cons concerned the costs, health hazards, and social disapproval. Participants were categorized in the 5 stages of change regarding their smoking status (ie, precontemplation, contemplation, preparation, action, and maintenance). The research confirmed that pregnancy-tailored messages in an intervention program could be an effective way to maximize impact. Lillington ${ }^{9}$ also reported that culturally appropriate, low-literacy materials are useful in delaying relapse or maintaining cessation.

Various cessation strategies have been offered to aid women in cessation attempts, including monitoring clinical interventions, ${ }^{30}$ tracking the success of written cessation aids-distributed in clinics ${ }^{11}$ and via mail ${ }^{37}$-and training health care providers on cessation interventions. ${ }^{41}$ Many programs have piggybacked with programs such as Women, Infants, and Children; Medicaid; health maintenance organizations (HMOs), and other organized, standardized, prenatal programs. ${ }^{6,42,43}$ Some people have tried more unusual methods of reaching pregnant smokers, for example through videotape, ${ }^{42}$ digitally interactive programs, ${ }^{38}$ and peer telephone support. ${ }^{30}$ Most of these programs have combined intervention strategies, hoping to increase success rates.

The general opinion is that clinical and social intervention cessation programs that would be most effective are those that address the needs of the individual woman, address her social network, and are incorporated into routine health care. Health care providers should tailor programs to the individual woman by distinguishing between women with concrete plans to prevent relapse and those who have not considered the possible challenges. ${ }^{34}$ The programs should also include personal interaction with clinicians and/or support staff. $^{42}$ Furthermore, providers should educate women about the dangers of exposure to environmental tobacco smoke, ${ }^{5,28}$ and about the risks of smoking for the woman, not just the baby. ${ }^{21}$ They should address a woman's social sphere by increasing community awareness about why women who are pregnant should not smoke, ${ }^{22}$ encouraging a woman's social network to support her with positive encouragement rather than negative nagging, ${ }^{30,34,39}$ and including her partner and others living in the home in any cessation effort. ${ }^{20,25,28,39,40}$ Programs must be included in routine health care, ${ }^{1,28}$ and begin as early as possible and last as long as possible, from prepregnancy, ${ }^{20,28}$ throughout pregnancy, ${ }^{1}$ immediately after delivery, ${ }^{20}$ and through breast-feeding. ${ }^{34}$ Finally, these programs must incorporate the time and financial commitment that successful cessation interventions require. ${ }^{25,37,43}$

\section{Interventions to Prevent Postpartum Relapse}

Relatively few studies have specifically examined cessation throughout pregnancy and postpartum..$^{11,14,18,44-52}$ The focus of most studies was not specifically on prevention of relapse, but rather on maintaining cessation throughout pregnancy and beyond. These programs were often offered in tandem with broader social service programs. ${ }^{23,24}$

Although intervention programs that seem effective at preventing postpartum relapse are similar to those that encourage cessation, key differences exist. Programs that successfully reduce postpartum relapse rates, even though they are specifically designed to reduce prepartum smoking rates, are those that include the smoking habits of partners, others living in the home, and close friends; ${ }^{6,31}$ support women with positive encouragement rather than negative nagging; ${ }^{6,24}$ understand the time and financial commitment successful cessation interventions require; ${ }^{23}$ encourage women's social networks to support her; ${ }^{31}$ take place throughout pregnancy $^{31}$ and through early childhood care; ${ }^{15}$ and distinguish between women with concrete plans for not relapsing and those who have not thought out possible challenges. ${ }^{6}$

Several themes are elaborated on in studies focusing solely on prevention of postpartum relapse. Through interviews with 27 women, Bottorof et $\mathrm{al}^{44}$ revealed the complex factors that are part of postpartum relapse. They identified 5 general story lines that explain why a woman who had quit dur- 
ing pregnancy might return to smoking after delivery: 1) controlling one's smoking (starting with one puff, restricting the amount smoked); 2) vulnerability to smoking (inability to resist); 3) nostalgia for former self (freedom and happier times); 4) smoking for relief (to manage emotions and stress); and 5) never really having quit (did not want to quit for themselves).

As noted previously, the woman's stage of readiness to quit will determine whether she will quit and what cessation approach to use. The percentage of women who returned to postpartum smoking was highest in the precontemplation stage and decreased with each subsequent stage. ${ }^{50}$ In another study that examined stage of change and use of brief motivational interviewing techniques during prenatal and postnatal visits, Valanis et $\mathrm{al}^{51}$ found that relapse rates were significantly lower than those of women in the comparison group. Other factors that might contribute to postpartum relapse are African American race/ethnicity, multiparity, late or no prenatal care, maternal weight gain, stressful life events, ${ }^{45}$ and early weaning. ${ }^{49}$

Many women clearly require unique relapse prevention interventions. Several studies reveal that clinical interventions are the primary method of cessation counseling. A survey of community health center providers scored performance of smoking cessation counseling steps offered to mothers, based on the National Cancer Institute's 4 A-steps of smoking cessation counseling: assessment of smoking status, advice to quit, assistance in staying quit, and arrangement for a follow-up. This composite measure of providers' self-reported smoking intervention practices and performance found that providers in obstetrics clinics had the highest performance scores and providers in pediatric clinics had the lowest scores. Nurse practitioners and nutritionists had higher scores than other providers (eg, program staff, obstetricians, and pediatricians). Low scores for performance of steps beyond assessment and advice indicate a need for emphasis on the assistance and arrangement for follow-up steps. ${ }^{53}$

Another intervention program offered telephone support postpartum by nurses to women at the time of delivery. This program was successful in decreasing relapse rates as well as in decreasing the amount of cigarettes smoked by women who did relapse. The study also found that 4 variables were associated with relapse to daily smoking. Breast-feeding and mental health were protective factors, whereas partners who smoked and the greater amount smoked before pregnancy had adverse effects. ${ }^{18,48}$

One intervention referred women to individual behavior change counseling during prenatal care in addition to standard cessation counseling from her physician. Although additional cessation counseling did not yield significantly lowered relapse rates, researchers found that greater proportions of the intervention group reported either not smoking or reducing their consumption by $50 \%$ or more. Researchers concluded that the following would have an impact on relapse rates: physician training on how to gain a pregnant smokers' commitment to change her smoking behavior, an office prompt system, and individualized smoking behavior change counseling. ${ }^{14}$

Not all studies show that advice from clinicians is the only way to offer relapse prevention messages. In a study of 57 low-income, multiethnic mothers and smokers, focus group discussions show that participants valued advice from friends and relatives over advice from professionals. Educational efforts might be most effective when directed at networks of women who share information. ${ }^{46}$

Although some programs did not see significant increases in postpartum relapse rates, researchers still suggested that successful relapse prevention programs should be added to cessation interventions, with increased duration and potency. ${ }^{11,52}$ These programs should include messages aimed at bolstering confidence in being able to continue not smoking, ${ }^{52}$ and be delivered throughout prenatal, postpartum, ${ }^{48}$ and early childhood care. Finally, these programs should be presented to the woman and her social network by ancillary staff (Table 2). ${ }^{52}$

\section{Further Research and Recommendations}

Based on the work published so far, we believe that clinicians and programs can improve the chances of women staying smoke-free after successful quitting during pregnancy by appropriate assessment and anticipatory guidance. Clinicians can quickly ask pregnant women about their decisions for quitting, their expectations for remaining smoke-free, their social support network, their beliefs about positive impacts of cessation, their potential for relapse, and events specific to the stresses in the postpartum period (Figure 1). For each of these constructs, current intervention research suggests possible answers to improve counseling effectiveness. 


\begin{tabular}{|c|c|c|c|}
\hline & Assessment & & Anticipatory Guidance \\
\hline \multirow[t]{3}{*}{$\begin{array}{l}\text { Decision for } \\
\text { Quitting }\end{array}$} & $\begin{array}{l}\text { Did she make the decision to quit based on a } \\
\text { desire to live a healthy lifestyle? }\end{array}$ & NO & $\begin{array}{l}\text { Relapse prevention to encourage continued } \\
\text { cessation as part of general health for woman, } \\
\text { not just baby. }\end{array}$ \\
\hline & Did she quit early in her pregnancy? & NO & $\begin{array}{l}\text { Give positive encouragement for continued } \\
\text { cessation. }\end{array}$ \\
\hline & YES & & . \\
\hline \multirow[t]{2}{*}{ Expectations } & Is her expectation to remain a non-smoker? & NO & $\begin{array}{l}\text { Relapse prevention to address woman's } \\
\text { readiness to change and self-efficacy. Bolster } \\
\text { woman's confidence, yet acknowledge that we } \\
\text { are least able to help those with low intentions } \\
\text { to quit. }\end{array}$ \\
\hline & YES & & \\
\hline \multirow[t]{2}{*}{\begin{tabular}{|l|} 
Social \\
Support
\end{tabular}} & Does she receive support and encouragement? & NO & $\begin{array}{l}\text { Include partner's, family's, and close friend's } \\
\text { smoking status in relapse prevention guidance } \\
\text { Encourage social support network. }\end{array}$ \\
\hline & YES & & \\
\hline \multirow[t]{2}{*}{\begin{tabular}{|l|} 
Incentivel \\
Barriers
\end{tabular}} & $\begin{array}{l}\text { Does she recognize how becoming smoke free } \\
\text { has positively impacted her life? }\end{array}$ & NO & $\begin{array}{l}\text { Educate about exposure to ETS, while } \\
\text { pregnant and after baby is born. }\end{array}$ \\
\hline & YES & & \\
\hline \multirow[t]{2}{*}{$\begin{array}{l}\text { Potential } \\
\text { Relapse }\end{array}$} & $\begin{array}{l}\text { Has she anticipated and planned solutions for } \\
\text { future temptations (i.e. return to non-pregnant } \\
\text { state, social pressures and high-risk situations)? }\end{array}$ & NO & $\begin{array}{l}\text { Develop relapse prevention plan: social skills } \\
\text { training; educate about stimulus priming effect. }\end{array}$ \\
\hline & YES & & \\
\hline \multirow[t]{2}{*}{$\begin{array}{l}\text { Pregnancyl } \\
\text { Postpartum }\end{array}$} & $\begin{array}{l}\text { During pregnancy/postpartum, is she exposed to } \\
\text { stressful events that may trigger a relapse (i.e. } \\
\text { relationship/medical problems)? }\end{array}$ & YES & $\begin{array}{l}\text { During prenatal and early childhood care visits, } \\
\text { explore unique stressors that may contribute to } \\
\text { a return to smoking. }\end{array}$ \\
\hline & $\begin{array}{l}\text { Does she plan to remain quit now that her baby } \\
\text { is born? }\end{array}$ & NO & $\begin{array}{l}\text { Encourage breastfeeding for six months. } \\
\text { Bolster confidence and give positive } \\
\text { encouragement for continued cessation during } \\
\text { hospital stay and well-baby visits. }\end{array}$ \\
\hline
\end{tabular}

DESIRE MODEL
\begin{tabular}{|l|l|}
\hline D & Decision \\
\hline E & Expectations \\
\hline S & Social support \\
\hline I & Incentives \\
\hline R & Relapse potential \\
\hline E & Encourage (breastfeeding), explore (stressors) \\
\hline
\end{tabular}

Figure 1. Pregnancy and postpartum smoking relapse prevention.

It is clear that additional research is needed to improve on the high relapse rates for smoking among pregnant women. For instance, research is needed that examines how the following optimally influence relapse prevention: stages of change, ${ }^{17}$ confidence level, ${ }^{3}$ perception of level of ease of quitting, ${ }^{3}$ and support systems. ${ }^{34,41}$ Interventions that involve the woman's partner ${ }^{34,41}$ need further exploration. Some researchers propose extending smoking cessation programs into the postpartum period $^{12,18,34}$ or as a part of well-baby care. ${ }^{11}$ The effects, costs, and outcomes of program extension have implications for developing a theoretic model of postpartum relapse and maintenance and for planning and implementing effective interventions.

Recent surveys of clinicians and providers have shown that providers reported low awareness of health risks of smoking to the fetus and child. ${ }^{54}$ 
Most providers feel they offer inadequate cessation counseling for women who smoke while pregnant. Those programs that do provide counseling do not assess smoking status before pregnancy or the smoking status of other household members, ${ }^{55}$ both of which are strong factors in postpartum relapse.

Maintaining and accelerating progress in smoking cessation during pregnancy and postpartum will require more research that focuses on relapse prevention in addition to cessation. To maximize effectiveness, programs should incorporate stresses particular to postpartum women, be part of routine health care, and involve the woman's social support network, including her partner.

We gratefully acknowledge support of our Smoke-Free Families Program from The Robert Wood Johnson Foundation (grant 040668).

\section{References}

1. Orleans CT, Johnson RW, Barker D, Kaufman N, Marx J. Helping pregnant smokers quit: meeting the challenge of the next decade. West J Med 2001;174: 276-81.

2. Ebrahim SH, Floyd RL, Merritt RK, Decoufle P, Holtzman D. Trends in pregnancy-related smoking rates in the United States, 1987-1996. JAMA 2000; 283:361-6.

3. Panjari M, Bell RJ, Astbury J, Bishop SM, Dalais F, Rice GE. Women who spontaneously quit smoking in early pregnancy. Aust NZ J Obstet Gynecol 1997; 37:271-8.

4. Windsor RA, Cutter G, Morris J, et al. The effectiveness of smoking cessation methods for smokers in public health maternity clinics: a randomized trial. Am J Public Health 1985;75:1389-92.

5. Fingerhut LA, Kleinman JC, Kendrick JS. Smoking before, during, and after pregnancy. Am J Public Health 1990;80:541-4.

6. Gielen AC, Windsor R, Faden R, O'Campo P, Repke J, Davis M. Evaluation of a smoking cessation intervention for pregnant women in an urban prenatal clinic. Health Educ Res 1997;12:247-54.

7. Hjalmarson AIM, Hahn L, Svanberg B. Stopping smoking in pregnancy: effect of a self-help manual in controlled trial. Br J Obstet Gynecol 1991;98:260-4.

8. Kendrick JS, Zahniser C, Miller N, et al. Integrating smoking cessation into routine public prenatal care: the smoking cessation in pregnancy project. Am J Public Health 1995;85:217-22.

9. Lillington L, Royce J, Novak D, Ruvalcaba M, Chlebowski R. Evaluation of a smoking cessation program for pregnant minority women. Cancer Pract 1995;3:157-63.

10. Mayer JP, Hawkins B, Todd R. A randomized eval- uation of smoking cessation interventions for pregnant women at a WIC clinic. Am J Public Health 1990;80:76-8.

11. McBride CM, Curry SJ, Lando HA, Pirie PL, Grothaus LC, Nelson JC. Prevention of relapse in women who quit smoking during pregnancy. Am J Public Health 1999;89:706-11.

12. Mullen PD, Quinn VP, Ershoff DH. Maintenance of nonsmoking postpartum by women who stopped smoking during pregnancy. Am J Public Health 1990;80:992-4.

13. Panjari M, Bell RJ, Bishop SM, Astbury J, Rice GE, Doery J. A randomized controlled trial of a smoking cessation intervention during pregnancy. Aust NZ J Obstet Gynecol 1999;39:312-7.

14. Secker-Walker RH, Soloman LJ, Flynn BS, et al. Individualized smoking cessation counseling during prenatal and early postnatal care. Am J Obstet Gynecol 1994;171:1347-55.

15. Walsh RA, Redman S, Brinsmead MW, Byrne JM, Melmeth A. A smoking cessation program at a public antenatal clinic. Am J Public Health 1997;87: 1201-4.

16. Walsh RA, Lowe JB, Hopkins PJ. Quitting smoking in pregnancy. Med J Aust 2001;175:320-3.

17. Haslam C. Maternal factors, obstetric history and smoking stage of change. J Public Health Med 1999; 21:185-91.

18. Johnson JL, Ratner PA, Bottorff JL, Hall W, Dahinten S. Preventing smoking relapse in postpartum women. Nurs Res 2000;49:44-52.

19. Hakansson A, Lendahls L, Petersson C. Which women stop smoking? A population-based study of 403 pregnant smokers. Acta Obstet Gynecol Scand 1999;78:217-24.

20. DiClemente CC, Dolan-Mullen P, Windsor RA. The process of smoking during pregnancy: implications for interventions. Tob Control 2000;9 Suppl 3:III16-21.

21. Bane CM, Ruggiero L, Dryfoos JM, Rossi JS. Development of a pregnancy-tailored decisional balance measure for smoking cessation. Addict Behav 1999;24:275-9.

22. Cnattingius S, Lindmark G, Meirik O. Who continues to smoke while pregnant? J Epidemiol Community Health 1992;464:218-21.

23. Dolan-Mullen PD, DiClemente CC, Velasquez $M M$, et al. Enhanced prenatal case management for low income smokers. Tob Control 2000;9 Suppl 3:III75-7.

24. Donatelle RJ, Prows SL, Champeau D, Hudson D. Randomised controlled trial using social support and financial incentives for high risk pregnant smokers: significant Other Supporter (SOS) program. Tob Control 2000;9 Suppl 3:III67-9.

25. Ershoff DH, Solomon LJ, Dolan-Mullen P. Predictors of intentions to stop smoking early in prenatal care. Tob Control 2000;9 Suppl 3:III41-5.

26. Haslam C, Draper E, Goyder E. The pregnant 
smoker: a preliminary investigation of the social and psychological issues. J Public Health Med 1997;19: 187-92.

27. Isohanni M, Oja H, Moilanen I, Koiranen M, Rantakallio P. Smoking or quitting during pregnancy: associations with background and future social factors. Scand J Soc Med Suppl 1995;23:32-8.

28. Lu Y, Tong S, Oldenburg B. Determinants of smoking and cessation during and after pregnancy. Health Promot 2001;16:355-65.

29. Owen L, McNeill A, Callum C. Trends in smoking during pregnancy in England, 1992-1997: quotasampling surveys. BMJ 1998;317:728-30.

30. Solomon LJ, Secker-Walker RH, Flynn BS, Skelly JM, Capeless EL. Proactive telephone peer support to help pregnant women stop smoking. Tob Control 2000;9 Suppl 3:III72-4.

31. Mullen PD, Richardson MA, Quinn VP, Ershoff DH. Postpartum return to smoking: who is at risk and when. Am J Health Promot 1997;11:323-30.

32. Windsor R, Woodby L, Miller T, Hardin J, Crawford M, DiClemente CC. Effectiveness of Agency for Health Care Policy and Research clinical practice guidelines and patient education methods for pregnant smokers in Medicaid maternity care. Am J Obstet Gynecol 2000;182:68-75.

33. Kahn RS, Certain L, Whitaker RC. A reexamination of smoking before, during, and after pregnancy. Am J Public Health 2002;92:1801-8.

34. Edwards N, Sims-Jones N. Smoking and smoking relapse during pregnancy and postpartum: results of a qualitative study. Birth 1998;25:94-100.

35. Bullock F, Mears JL, Woodcock C, Record R. Retrospective study of the association of stress and smoking during pregnancy in rural women. Addict Behav 2001;26:405-13.

36. Hymowitz N, Schwab M, McNerney C, Schwab J, Eckholdt H, Haddock K. Postpartum relapse to cigarette smoking in inner city women. J Natl Med Assoc 2003;95:461-74.

37. Ershoff DH, Mullen PD, Quinn VP. A randomized trial of a serialized self-help smoking cessation program for pregnant women in an HMO. Am J Public Health 1989;79:182-7.

38. Scott $W$, McIlvain H. Interactive software: an educational/behavioral approach to smoking cessation for pregnant women and their families. Tob Control 2000;9 Suppl 3:III56-7.

39. Haslam C. A targeted approach to reducing maternal smoking. Br J Gen Pract 2000;50:661-3.

40. Nafstad P, Botten G, Hagen J. Partner's smoking: a major determinant for changes in women's smoking behavior during and after pregnancy. Public Health 1996;110:379-85.

41. Velasquez M, Hecht J, Quinn V, Emmons K, DiClemente CC, Dolan-Mullen P. Application of motivational interviewing to prenatal smoking cessa- tion: training and motivational issues. Tob Control 2000;9 Suppl 3:III36-40.

42. Cinciripini P, McClure J, Wetter D, et al. An evaluation of videotaped vignettes for smoking cessation and relapse prevention during pregnancy: the Very Important Pregnant Smokers (VIPS) program. Tob Control 2000;9 Suppl 3:III61-3.

43. Klerman L, Spivey C, Raykovich K. Smoking reduction activities in a federal program to reduce infant mortality among high-risk women. Tob Control 2000;9 Suppl 3:III51-5.

44. Bottorff JL, Johnson JL, Irwin LG, Ratner PA. Narratives of smoking relapse: the stories of postpartum women. Res Nurs Health 2000;23:126-34.

45. Carmichael SL, Ahluwalia IB. Correlates of postpartum smoking relapse. Results from Pregnancy Risk Assessment Monitoring System (PRAMS). Am J Prev Med 2000;19:193-6.

46. Dunn CL, Pirie PL, Lando HA. Attitudes and perceptions related to smoking among pregnant and postpartum women in a low-income, multi-ethnic setting. Am J Health Promot 1998;12:267-74.

47. Lando HA, Valanis BG, Lichtenstein E, Curry SJ, McBride CM, Pirie PL. Promoting smoking abstinence in pregnant and postpartum patients: a comparison of two approaches. Am J Manag Care 2001; 7:685-93.

48. Sheahand Sl, Wilson SM. Smoking cessation for pregnant women and their partners: a pilot study. J Am Acad Nurse Pract 1997;9:323-6.

49. Ratner PA, Johnson JL, Bottorff JL. Smoking relapse and early weaning among postpartum women: is there an association? Birth 1999;26:76-82.

50. Stotts AL, DiClemente CC, Carbonari JP, Mullen PD. Postpartum return to smoking: staging a "suspended" behavior. Health Psychol 2000;19:324-32.

51. Valanis BG, Lichtenstein E, Mullooly JP, et al. Maternal smoking cessation and relapse prevention during health care visits. Am J Prev Med 2001;20:1-8.

52. Van't Hof S, Wall M, Dowler D, Stark M. Randomized control trial of a postpartum relapse prevention intervention. Tob Control 2000;9 Suppl 3:III64-6.

53. Zapka JG, Pbert L, Stoddard AM, Ockene JK, Goins $\mathrm{KV}$, Bonollo D. Smoking cessation counseling with pregnant and postpartum women: a survey of community health center providers. Am J Public Health 2000;90:78-84.

54. Bonollo DP, Zapka JG, Stoddard AM, Ma Y, Pbert $\mathrm{L}$, Ockene JK. Treating nicotine dependence during pregnancy and postpartum: understanding clinician knowledge and performance. Patient Educ Couns 2002;48:265-74.

55. Klerman LV, Spivey C. Smoking-related activities in prenatal care programs. Am J Prev Med 2003;25: 129-35.

56. Ratner PA, Johnson JL, Botoroff JL, Dahinton S, Hall $W$. Twelve-month follow-up of a smoking relapse prevention intervention for postpartum women. Addict Behav 2000;25:81-92. 